\title{
Predicting early adoption of successive video player generations
}

\author{
Frank J. van Rijnsoever ${ }^{\mathrm{a}, *}$, Harmen Oppewal ${ }^{\mathrm{b}, 1}$ \\ a Utrecht University, Copernicus Institute of Sustainable Development, Heidelberglaan 2, 3584 Utrecht, The Netherlands \\ b Monash University, Department of Marketing, Faculty of Business and Economics, 26 Sir John Monash Drive, Caulfield East, VIC 3145, Australia
}

\section{A R T I C L E I N F O}

\section{Article history:}

Received 5 April 2011

Received in revised form 10 August 2011

Accepted 13 August 2011

Available online 13 September 2011

\section{Keywords:}

Early adoption

Innovation

Product generations

Home entertainment market

\begin{abstract}
A B S T R A C T
Early adopters play an important role in the innovation diffusion process. Over the past decades, many factors have been identified as predictors for early adoption of innovations. Less attention has been paid to the relationship between the early adoption of one generation of a specific product and the early adoption of successive product generations. This paper analyzes how early adoption of a new product generation depends on ownership, purchase experience and adoption times for previous generations of the same product. The paper develops predictive models of early adoption for four generations of video player products, based on a survey among 815 Australian consumers. The model allows the testing of various hypotheses. It is shown that previous generation variables outperform conventional socio-demographic and psychographic variables in predicting early adoption but also that the two variable types complement each other. The best predicting models include both previous generation and socio/psychographic variables. It is concluded that previous generation models have substantial merits for new product forecasting as they are more parsimonious than conventional models and the data required to estimate them is relatively easy to obtain.
\end{abstract}

(c) 2011 Elsevier Inc. All rights reserved.

\section{Introduction}

The home-entertainment market is a large market that is characterized by continuous innovation and increasingly rapid succession of product generations. In 2008, an estimated 25 million DVD players and about 10 million Blu-ray systems were sold in the United States alone. The combined consumer spending on DVD home entertainment in that country exceeded \$22 billion [1]. Due to its size and characteristics it is important in this market to be able to predict which consumers are likely to be early adopters of new product generations.

Early adopters are the first consumers that adopt an innovation new to the market. Rogers [2] states that approximately $16 \%$ of the market are early adopters, though this number is criticized by others [3]. Consumers adopt early because they are intrinsically motivated, because they expect certain benefits from the new product, or because of situational reasons such as social pressure [4]. Consumers who want to avoid uncertainty or want to wait until the price of the product falls are likely to be among the later adopters [for the full set of motivations at the time of adoption, see 2,5]

These early adopters play an important role in the innovation diffusion process. By being the first to trial new products $[2,4,6]$, they help test the product's functionality and thereby contribute to product development [7,8]. Early adopters also help disseminate the characteristics and functionality of the new product to other consumers. This is because they can serve as opinion leaders that introduce new norms and ideas into a social system $[9,10]$. Additionally, in the case of interdependent innovations, the early adoption of products enables the build-up of what is called 'critical mass', the point after which the diffusion of the innovation becomes self-sustaining [2].

\footnotetext{
* Corresponding author at: Heidelberglaan 2, 3584 Utrecht, The Netherlands. Tel.: +31 302537484 ; fax: + 31302532746.

E-mail addresses: f.j.vanrijnsoever@uu.nl (F.J. van Rijnsoever), Harmen.Oppewal@buseco.monash.edu.au (H. Oppewal).

1 Tel.: +61399032360.
} 
Over the past decades, many factors have been identified as predictors of early adoption of innovations. These factors can largely be grouped as innovation characteristics, (social) environmental characteristics, and personal characteristics [see 2,11,12]. One of the personal characteristics that influence time of adoption is the previous experience with other, related products in the same category $[13,14]$. The more experience the adopter has with related products, the more likely it is that the consumer will adopt the new product; this phenomenon is called technology clustering [15-17].

The influence of current ownership of related products on the likelihood of early adoption has been researched quite extensively [see 13,18,19]. Less attention has been paid to the relationship between the early adoption of one generation of a specific product and the early adoption of successive product generations. In successive product generations the basic functionalities or service characteristics remain similar while technical characteristics can differ [see 20].

Adoption patterns of successive product generations are not well understood. Some studies focus on successive product generations from a diffusion perspective [i. e. 21-25], while others adopt a technological evolutionary perspective [see 26,27]. Almost no studies focus explicitly on the adoption of product generations from an individual consumer perspective. Kim et al. [28] model purchase probabilities for successive PC generations as a function of purchase history, buyer expectations of future generations and preferences for currently available options. Finally, Sääksjärvi and Lampinen [29] study how usage experience with a previous generation plays a role in perceived risk of adopting a successive generation.

The aim of this paper is to use previous generation adoption data to predict the likelihood of early adoption. As this paper will show, this type of data can be used in relatively simple models that are quite effective predictors for the early adoption of successive generations. We also assess how this model performs relative to a model with conventional predictors such as sociodemographics and consumer attitudinal constructs. Comparison against such a benchmark allows assessing the contribution of previous adoption behavior as a predictor of early adoption. The advantage of using previous generation adoption data is that this type of data is relatively easy to obtain. It may be readily available in customer databases or it can be obtained by asking customers about their previous product generation adoption behaviors. Asking for such information is less intrusive than asking attitudinal and socio-demographic information as required for other predictive models.

Our empirical data is derived from the Australian home-entertainment market. Therefore the paper starts with providing a short description of the various video play product generations. It then presents the theoretical rationale. Next follow the methodology and empirical results. The paper concludes with a discussion of the study's theoretical and managerial implications and its limitations. Although the paper focuses on the domain of video play products the findings have a wider relevance as they suggest similar patterns of results may be observable for other product domains in which several generations of products succeed each other.

\section{The home entertainment market}

The home entertainment market started in the 1970s when the first formats for home Video Cassette Recorders (VCR) were launched. In 1976 the VCR was introduced on the Australian market, which is where the current study was conducted. VHS eventually ended up as the dominant VCR format [30]. The end of the 1990s saw the introduction of the Digital Versatile Disc (DVD) as the new standard for high quality video. DVD disks store more data than videotapes, allowing for a better image quality. DVD-players were introduced in 1997, with the first DVD recorders being introduced soon after, in 1999. Storage capacity remained the main limiting factor. The next generation 'high definition' disk technology increased the capacity of a single disk from approximately $4 \mathrm{~Gb}$ to between 20 and $50 \mathrm{~Gb}$, depending on the type of system. Two rivaling consortia were involved in the development of this high definition disk technology, each developing its own format. This resulted in a format war between two high definition formats: HD DVD and Blu-ray. The format war ended early 2008 with Blu-ray becoming the new video standard. Parallel to these developments in recording technology, a system was also introduced that automatically and continuously records TV programs on a local hard drive, customized to the user's preferences. Identified as Personal Video Recorder (PVR), these systems, especially TiVo, were available in the US since 1999 in various forms. In Australia this PVR system became available only during 2008 and at the time of data collection was the latest product generation in this category.

Previous studies on product generations have investigated product categories in which successive generations follow relatively rapidly and are closely related in terms of technological characteristics and functionality, for example: PCs [28] or Mobile Phones [29]. The case of video play products differs somewhat from these. With each following generation the core storage technology changed, but the functionality remained largely the same and was extended over time. The basic functionality of video play is the ability to play video content. In most cases there is also an ability to record content instead of only playing pre-recorded material. Each generation adds certain functionalities, such as an enhanced image quality, or optional subtitles. Finally, the time between the generations has been decreasing, which makes it more likely that consumers will skip a generation.

\section{Model and hypothesis development}

Previous generation adoption behavior can be described in different ways. The discussion will first focus on specifying effects of the availability of, and purchase experience with previous product generations. Then time of adoption and the effects of having multiple generations within one product are considered. This leads to the formulation of benchmark models that include 'traditional' predictors such as socio- and psycho-demographics. 


\subsection{Previous generation model}

\subsubsection{Availability of a previous generation}

The literature suggests that consumers who already are familiar with a product are more likely to be early adopters of a related product [2,31]. Familiarity can be a result of mere availability of the product. Having a product available in the household will increase a consumer's familiarity with it. There are different ways in which a product can become available for use in a household. Typically the consumer will have purchased the product personally. However the product might also be a gift or have been purchased by another household member. If consumers are familiar with a previous generation they are able to utilize their existing knowledge to learn about a following generation [29,32].

As they become familiar with a product consumers will learn about the technical characteristics of the product (how it works) and about the functional (or service) characteristics (what it does) [33]. As across generations there is less change of functional characteristics than of technical characteristics the functional knowledge in particular will prepare them for adopting the newer generation. Experiences with the product's functionality give the consumer an ability to interpret new innovations and to detect superior new functionalities $[13,34]$. This leads to a higher likelihood of early adoption compared to consumers who did not enjoy the experiential benefits from the previous generation. We therefore hypothesize:

H1. Consumers who have had a previous product generation item available for use in their household are more likely to be early adopter of the successive product generation than consumers who did not have such an item available.

\subsubsection{Purchase experience}

Adopters can obtain new products from various sources including receiving them for trial or as gifts (either wanted or unwanted). However in the majority of cases they will purchase the product themselves. This implies that consumers have to expend effort to obtain the product: they have to search for information prior to purchasing, evaluate available alternatives and need to decide and make the actual purchase [35]. This active engagement in the purchase process results in the consumer becoming more experienced with the product and with various aspects of the purchase process [36]. Those consumers who had a successful purchase experience are therefore more likely to repeat the same behavior in the future [37], compared to those without the experience. Therefore, if a consumer has purchased a previous generation of a products him/herself, the likelihood increases that he/she is an early adopter of a successive generation. We hypothesize:

H2. Consumers who purchased a previous product generation are more likely to also be early adopters of a successive generation than those who did not purchase a previous generation.

\subsubsection{Time of adoption}

In addition to the availability and purchase of a previous generation, the time a previous generation was adopted seems to have an effect on the likelihood of early adoption. Van Rijnsoever and Donders [31] identify a positive correlation between the time of adopting a personal computer and the time of adopting the Internet. There are several possible reasons for this relationship. First, people who are early adopters generally derive a higher utility from the product than those adopting late [2]. For example, someone who enjoys watching movies will derive greater utility from a video player, and hence be more likely to adopt the newest product generation, than someone who does not like watching movies. Second, early adopters of an innovation are often characterized as being more involved [3,31], being heavy users, or even being lead users [2,13,38]. Involved consumers and heavy users have more experience with the functionalities of the previous generation and are thus better able to identify superior alternatives at an earlier stage than later adopters. Third, due to wear and tear, the longer the time since the last repeat purchase, the stronger the desire or need for upgrading [39], which increases the chance of early adoption. Fourth, involved consumers may also perceive an inherent need to remain up to date with the product [40,41], which increases their likelihood of early adoption. Fifth, being a heavy user of a certain product can become a part of a consumer's identity, further prompting consumers to early adopt $[42,43]$. Therefore we expect that:

H3. Consumers who were earlier adopters of a previous product generation are more likely to be early adopters of a successive generation than those who did not early adopt a previous generation.

\subsubsection{Multiple previous generations}

Many product categories see continuous innovation resulting in multiple product generations co-existing in the marketplace. When considering adoption behavior, the question arises which previous generation is the best predictor of early adoption of a new generation if multiple generation co-exist. We propose that variables relating to the most recent generation are the best predictors of early adoption. Consumers use their experiences with the closest related product to assess the benefits of the new generation [33]. The closest related product will be the most recent generation, especially when the technology and its functionality have evolved over time due to the invention of new applications [20]. Moreover, not only do products evolve, consumer preferences evolve too as consumers gain experience with new products and product characteristics [44,45], prompting them to adopt new products that better match these evolved preferences. Finally, early adopters of older generations are more likely to be no longer in the market. For example, consumers who were early adopters of the VCR may have lost their interest in home entertainment products or they may even have passed away by the time Blu-ray was released on the market. The longer the 
time scale over which generations are observed, the more pronounced this effect is expected to be. Ownership of and experience with the most recent generation is therefore proposed the main determining factor of the extent to which consumers will adopt the newest product generation. We therefore propose:

H4a. The availability in a consumer's home of the most recent product generation is a better predictor of the likelihood of early adoption of a successive generation than the availability of an earlier generation.

H4b. Having purchased the most recent product generation is a better predictor of the likelihood of early adoption of a successive generation than having purchased an earlier generation.

H4c. The time of adoption of the most recent generation is a better predictor of likelihood of early adoption of a successive generation than the time of adoption of earlier generations.

\subsection{Benchmark model}

The previously discussed variables are all based on adoption of the previous generation product. In most studies however other types of variables are used to predict early adoption. These include socio demographic characteristics, attitudes towards innovation and the availability of other products related to the product under consideration. To assess how adoption of the previous generation compares against these variables in terms of predictive ability a model is also built that includes these more general variables. This model will be called the benchmark model.

\subsubsection{Socio-demographics}

Past studies reveal that socio-demographic characteristics are associated with early adoption [13,46], but that this effect is domain specific [47]. The explanatory value of socio-demographics therefore tends to be rather limited. Socio-demographics can nevertheless provide valuable information for marketers and are of practical relevance because this information is often readily available. The variables considered here are gender, age, income and education level. Gender has been found to influence early adoption of high-tech products with males being more likely to early adopt [31]. Younger consumers in general are more likely to be early adopters [48], however for products as studied here early adopters also have been found to be in the older age groups $[2,13]$. Higher education and income levels are generally associated with greater levels of early adoption [13]. We therefore state our hypothesis as follows:

H5. There is a significant relationship between early adoption a new product generation and socio-demographic variables. In particular, early adopters are more likely to be males (5a), from older cohorts (5b), have higher incomes (5c) and have higher levels of education (5d).

\subsubsection{Consumer innovativeness}

In consumer research the concept of innovativeness has been defined and analyzed at multiple levels $[6,49,50]$ ranging from global innovativeness as a personality trait; domain-specific innovativeness, which refers to the adoption within a group products; to product-specific innovativeness, which refers to the adoption of a single product. Since we study video play products, in this paper we consider several domain-specific attitudinal constructs that reflect consumers' innovativeness. Though attitudinal constructs are not always translated into behavior [51-53], these constructs are known to be positively related to adoption behavior [4,31,46], though some other studies found no relationship [e.g. 54].

In our study we include four measures that have been used in the literature to measure aspects of consumer innovativeness. We expect all of these to be significantly related to the likelihood that a consumer is an early adopter of a succeeding generation. The first measure is Consumer Novelty Seeking (CNS). It refers to the desire to seek out new product information and is associated with the early stages of the adoption process, which include the seeking of novel information [55]. We secondly consider Consumer Independent Judgment Making (CIJM), which measures the degree to which "an individual makes new product purchase decisions independently of the communicated experience of others" [4, p235, 55, p330] and is associated with the inclination to trial new products. A third measure for innovativeness is Dispositional innovativeness (DI) [6,56], which refers to the predisposition to purchase new products rather than to remain with previous consumption patterns [57]. DI has been found to be positively associated with consumer traits like optimum stimulation level, openness to change, independence, risk taking, venturesomeness, and tolerance of ambiguity, while being negatively related to dogmatism and conservation [57]. This measure has also been found to be positively related to early adoption [see 56], therefore we expect a positive relationship with early adoption of a succeeding generation. A final construct considered here is the Consumer Susceptibility to Normative Influence (CSNI), which refers to a consumer's tendency to conform to the expectations of other people [58]. Consumers with high susceptibility to normative influence are unlikely to make an adoption decision until it is clear that a majority of relevant others support the new innovation. A negative relationship between CSNI and early adoption of a succeeding generation can thus be expected. In summary we hypothesize:

H6. There is a significant relationship between consumer innovativeness and early adoption a new product generation. In particular, consumers are more likely to be early adopters if they score higher values on CNS (6a), CIJM (6b), DI (6c), and if they score lower values on CSNI (6d). 
Finally, given the arguments above we expect that past behavior captured by the previous generation variables will better predict early adoption of a new product generation than socio-demographic and attitudinal constructs. Further, it is possible that the previous generation variables mediate the relationship between the benchmark variables and the early adoption of a succeeding generation, because the benchmark variables are also predictors for the early adoption of the previous generation. The previous generation model thus captures part of the variance explained by the benchmark model:

H7. Models that only include previous generation variables will predict early adoption better than models only including sociodemographic and attitudinal constructs.

\section{Methods}

\subsection{Sample and data collection}

Data collection took place in Australia among a random sample of members of a nationwide online panel. Quotas for age, household composition and income categories ensured the sample would approximately represent the population of 18 years and over. Panel members received a small compensation for their participation. 863 respondents completed the questionnaire. The questionnaire asked respondents to indicate when they had adopted each of various video play products. Those who never had any of the products available were excluded from the sample, leaving a total of 815 for analysis of which $52.6 \%$ was female.

Respondents received a list of video player product generations comprising: VCR, DVD player, DVD recorder, Blu-ray player, HD DVD player and PVR recorder. They indicated for each if they had the product available in their household, either standalone or integrated into another product (yes or no), if they had ever purchased the standalone product themselves (yes or no) and if so, at what point in time they had first purchased the product as a standalone item (not adopted, 0 to 3 months ago, 4-6 months ago, 712 months ago, 1-2 years ago, 3-4 years ago, 5-7 years ago, 8-10 years ago, 11-14 years ago, 15-20 years ago, more than 20 years ago). By using these predefined intervals it was avoided that respondents would have to recall the exact year of purchase, thereby reducing the risk of recall bias. Based on this measure of time of adoption, respondents were classified as early adopters or late adopters. Because ordinal time intervals had been used it was not possible to precisely determine which respondents had been the first $16 \%$ to adopt; instead the interval boundary nearest to the 16th percentile was used as the cut-off to determine who was an early adopter. ${ }^{2}$

Measurement of socio-demographics characteristics involved direct questions about the respondent's gender, age, education and income levels. Age was measured in categories (1) 18-25 years, (2) 26-35 years, (3) 36-45 years, (4) 46-55 years, (5) 5665 years (6) over 65 years. Education level was measured by asking respondents which degree they had according to the Australian education system. Income was measured as annual household income in Australian dollars before tax, divided in nine categories ranging from 'less than $\$ 20,000$ ' to '\$180,000 or more'.

To measure the attitudinal constructs the study used 5-point scale items ( $1=$ does not describe me at all; $5=$ describes me very well). Items were from the CNS and CIJM scales by Manning et al. [55], the DI scale by Steenkamp and Gielens [56] and the CSNI scale by Bearden et al. [58]. ${ }^{3}$ Missing data (0.26\%) were imputed using the PRELIS 2.0 program [59] with multiple imputation [60]. Confirmatory factor analysis was used for each scale to assess its unidimensionality and derive factor scores for use in the further analysis. Cronbach alpha levels were satisfactory for all scales (CNS .90, CIJM .85, DI .71, CSNI .91). Further details on measurement and descriptive statistics are provided in Table 1. The correlation matrix is presented as Appendix A.

\subsection{Model estimation}

Model estimation involved the fitting of binary logistic regression models for each product generation, ${ }^{4}$ with being an early adopter of the product generation or not as the dependent variable. Availability, purchase and experience had been measured for Bluray and HD-DVD separately. However as these two disk technologies have the same functionality they were merged to a dummy that indicates if the respondent had adopted any of these two products. In total $9.7 \%$ of all respondents owned at least one of these current products.

Independent variables in the Previous Generation product adoption model include the availability of previous generations in the household, whether the respondent has purchased the previous generation him or herself, and the time of adoption of the previous generation. The results in Table 2 report the model $\chi^{2}$ and the Nagelkerke pseudo $\mathrm{R}^{2}$. Further, for each of the models a Receiver Operating Characteristic (ROC) curve is presented to determine if the model is better than random chance in predicting early adopters [61]. The larger the area under the curve, the better the model is at classifying early adopters correctly: a value of 0.5 means that the model predicts no better than random chance, a value between 0.7 and 0.8 means an acceptable fit, a value between 0.8 and 0.9 means an excellent fit.

\footnotetext{
${ }^{2}$ Rogers (2003) also distinguishes an innovator category, which consists of the first 2.5\% of the population. We ran the same analyses as described below for this specific group, but this did not produce any substantially different results.

${ }^{3}$ Some items from the original scales were deleted to keep the questionnaire as short as possible.

4 The same analyses were conducted using ordinal logit regression models with the time of adoption categories as dependent variables; these gave similar results. To enable a better comparison between the models we present the results of the binary logistic regression models. Binary logit models with other cut-off values gave similar results.
} 
Table 1

Measurement items and descriptive statistics.

\begin{tabular}{l}
\hline Variable \\
\hline Adoption variables \\
Early adoption DVD-player (5-7 years ago $)^{*}$ \\
Early adoption DVD-recorder $(1-2 \text { years ago })^{*}$ \\
Early adoption Blu-ray/HD-DVD player $(<3 \text { months ago })^{*}$ \\
Early adoption PVR (less than 3 months ago $)^{*}$ \\
Available VCR \\
Available DVD-player \\
Available DVD-recorder \\
Purchased VCR \\
Purchased DVD-player \\
Purchased DVD-recorder \\
Adoption time VCR
\end{tabular}

Adoption time DVD-player

Adoption time DVD-recorder

Sociodemographic variables

Gender

Age

Education level completed

Income

Scale items

I like to go to places where I will be exposed to information about new products and brands.

I frequently look for new products and services.

I seek out situations in which I will be exposed to new and different sources of product information.

I am continually seeking new product experiences.

I seldom ask a friend about his or her experiences with a new product before I buy the new product.

I decide to buy new products and services without relying on the opinions of friends who have already tried them.

When I am interested in purchasing a new service, I do not rely on my friends or close acquaintances that have already used the new service to give me information as to whether I should try it.

I do not rely on experienced friends for information about new products prior to making up my mind about whether or not to purchase.

When I see a new product on the shelf, I'm reluctant to give it a try.

I am very cautious in trying new and different products.

I do not like to buy a new product before other people do.

If I want to be like someone, I often try to buy the same brands that they buy.

It is important that others like the products and brands I buy.

I rarely purchase the latest fashion styles until I am sure my friends approve of them.

I often identify with other people by purchasing the same products and brands they purchase.

${ }^{*}$ For the early adoption variables, the last category considered as early adopter is given in brackets. All categories above this category are also coded as early adopter.
Descriptive (valid $\mathrm{N}=815)$

Yes: $124(15.2 \%)$

Yes: $89(10.9 \%)$

Yes: 79 (9.7\%)

Yes: $117(14.4 \%)$

Yes: $619(76.0 \%)$

Yes: $733(89.9 \%)$

Yes: $445(54.6 \%)$

Yes: $646(79.3 \%)$

Yes: $631(77.4 \%)$

Yes: $240(29.4 \%)$

None: 169 (20.7\%)

Less than 3 months ago: 10 (1.2\%)

3-5 months ago: 8 (1.0\%)

6-12 months ago: $7(.9 \%)$

$1-2$ years ago: $26(3.2 \%)$

2-4 years ago: $28(3.4 \%)$

$5-7$ years ago: $89(10.9 \%)$

8-10 years ago: 141 (17.3\%)

11-14 years ago: 126 (15.5\%)

15-20 years ago: 99 (12.1\%)

$>20$ years ago: 112 (13.7\%)

None: 184 (22.6\%)

Less than 3 months ago: 11 (1.3\%)

3-5 months ago: 13 (1.6\%)

6-12 months ago: $45(5.5 \%)$

1-2 years ago: 90 (11.0\%)

2-4 years ago: 175 (21.5\%)

5-7 years ago: 173 (21.2\%)

8-10 years ago: $102(12.5 \%)$

11-14 years ago: 22 (2.7\%)

None: 575 (70.6\%)

Less than 3 months ago: 18 (2.2\%)

3-5 months ago: 20 (2.5\%)

6-12 months ago: 47 (5.8\%)

$1-2$ years ago: $66(8.1 \%)$

2-4 years ago: $70(8.6 \%)$

5-7 years ago: $15(1.8 \%)$

$8-10$ years ago: $4(.5 \%)$

Female: 429 (52.6\%)

Median: 36-45 years

Median: Associate diploma

Median: $\$ 60,001-\$ 80,000$

CNS (Extracted variance: 77.8\%, Cronbachs Alpha: 0.904)

CIJM (Extracted variance: 68.6\%, Cronbachs Alpha: 0.846)

DI (Extracted variance: 63.2\%, Cronbachs Alpha: 0.709)

CSNI (Extracted variance: 77.8\%, Cronbachs Alpha: 0.905) 
Table 2

Logistic regression model results.

\begin{tabular}{|c|c|c|c|c|}
\hline Early adoption of: & DVD player & DVD recorder & Blu-ray player or HD-DVD player & PVR \\
\hline \multicolumn{5}{|c|}{ MODEL 1 (Previous generation model) } \\
\hline Constant & $0.03^{* * *}$ & $0.03^{* * *}$ & $0.02^{* * *}$ & $0.02^{* * *}$ \\
\hline \multicolumn{5}{|l|}{ Availability: } \\
\hline VCR & 1.05 & $2.98^{* *}$ & 1.30 & 0.75 \\
\hline DVD player & & $0.06^{* * *}$ & 0.78 & $5.51^{*}$ \\
\hline DVD recorder & & $2.73^{* *}$ & 1.04 & \\
\hline \multicolumn{5}{|l|}{ Purchased: } \\
\hline VCR & $5.55^{* * *}$ & 2.44 & 2.06 & 1.00 \\
\hline DVD player & & $7.31^{* * *}$ & 0.81 & $2.17^{*}$ \\
\hline DVD recorder & & & $2.61^{* *}$ & $1.71^{*}$ \\
\hline \multicolumn{5}{|l|}{ Adoption time: } \\
\hline VCR & $1.67^{* * *}$ & $1.2^{* *}$ & $0.86^{*}$ & 0.95 \\
\hline DVD player & & $1.65^{* * *}$ & 0.81 & $1.26^{*}$ \\
\hline DVD recorder & & & 0.78 & $0.75^{*}$ \\
\hline Model $\chi^{2}$ & $94.43^{* * *}$ & $101.60^{* * *}$ & $77.76^{* * *}$ & $40.47^{* * *}$ \\
\hline Model df & 3 & 6 & 9 & 9 \\
\hline Nagelkerke $\mathrm{R}^{2}$ & 0.19 & 0.24 & 0.19 & 0.09 \\
\hline Area under ROC & $0.76^{* * *}$ & $0.80^{* * *}$ & $0.78^{* * *}$ & $0.69^{* * *}$ \\
\hline \multicolumn{5}{|l|}{ MODEL 2 (Benchmark model) } \\
\hline Constant & $0.32^{*}$ & $0.05^{* * *}$ & $0.04^{* * *}$ & $0.14^{* * *}$ \\
\hline \multicolumn{5}{|l|}{ Sociodem and Attitudes: } \\
\hline Sex & $0.57^{* *}$ & 1.03 & 1.26 & 0.76 \\
\hline Age & 1.06 & $1.26^{* *}$ & 1.10 & 1.03 \\
\hline Education Level & 0.98 & $0.88^{*}$ & 1.05 & 0.98 \\
\hline Income & 1.03 & $1.19^{* *}$ & 1.09 & $1.16^{* *}$ \\
\hline CNS & 1.09 & 1.23 & 1.05 & 1.04 \\
\hline CIJM & 0.92 & 0.93 & 1.28 & 0.89 \\
\hline DI & $1.44^{* *}$ & $1.23^{*}$ & 0.93 & $1.39^{* *}$ \\
\hline CSNI & 0.83 & 0.75 & $1.38^{*}$ & $1.28^{*}$ \\
\hline Model $\chi^{2}$ & $33.04^{* * *}$ & $31.80^{* * *}$ & $19.55^{* * *}$ & $26.15^{* * *}$ \\
\hline Model df & 8 & 8 & 8 & 8 \\
\hline Nagelkerke $\mathrm{R}^{2}$ & 0.07 & 0.08 & 0.05 & 0.06 \\
\hline Area under ROC & $0.66^{* * *}$ & $0.68^{* * *}$ & $0.63^{* * *}$ & 0.53 \\
\hline \multicolumn{5}{|c|}{ MODEL 3 (Previous generation and benchmark model combined) } \\
\hline Constant & $0.07^{* * *}$ & $0.02^{* * *}$ & $0.01^{* * *}$ & $0.02^{* * *}$ \\
\hline \multicolumn{5}{|l|}{ Availability: } \\
\hline VCR & 1.11 & $3.02^{* *}$ & 1.29 & 0.75 \\
\hline DVD player & & $0.06^{* * *}$ & 0.77 & $5.22^{*}$ \\
\hline DVD recorder & & & $2.67^{* *}$ & 0.90 \\
\hline \multicolumn{5}{|l|}{ Purchased: } \\
\hline VCR & $7.78^{* * * *}$ & 2.19 & $2.70^{*}$ & 1.20 \\
\hline DVD player & & $7.18^{* * *}$ & 0.76 & 2.04 \\
\hline DVD recorder & & & $2.89^{* *}$ & $1.78^{*}$ \\
\hline \multicolumn{5}{|l|}{ Adoption time: } \\
\hline VCR & $1.88^{* * *}$ & $1.24^{*}$ & 0.90 & 0.98 \\
\hline DVD player & & $1.62^{* * *}$ & 0.87 & $1.24^{*}$ \\
\hline DVD recorder & & & 0.78 & $0.71^{*}$ \\
\hline \multicolumn{5}{|l|}{ Sociodem and attitudes: } \\
\hline Sex & $0.61^{*}$ & 1.24 & 1.11 & 0.71 \\
\hline Age & $0.72^{*}$ & 1.06 & 1.03 & 1.00 \\
\hline Education Level & 1.01 & 0.89 & 1.09 & 1.00 \\
\hline Income & 1.01 & $1.20^{*}$ & 1.04 & $1.14^{*}$ \\
\hline CNS & 1.05 & 1.14 & 1.02 & 0.98 \\
\hline CIJM & 0.86 & 0.92 & 1.23 & 0.89 \\
\hline DI & $1.39^{* *}$ & 1.14 & 0.91 & $1.35^{*}$ \\
\hline CSNI & 1.06 & 0.87 & 1.31 & $1.36^{*}$ \\
\hline Model $\chi^{2}$ & $125.37^{* * *}$ & $114.48^{* * *}$ & $91.06^{* * *}$ & $63.33^{* * *}$ \\
\hline Model df & 11 & 14 & 17 & 17 \\
\hline$\chi^{2}$ difference (relative to 1 ) & $30.94^{* * *}$ & 12.88 & 13.30 n.s. & $22.86^{* *}$ \\
\hline$\chi^{2}$ difference (relative to 2 ) & $92.33^{* * *}$ & $82.86^{* * *}$ & $71.50^{* * *}$ & $37.18^{* * *}$ \\
\hline Nagelkerke R2 & 0.25 & 0.26 & 0.22 & 0.13 \\
\hline Area under ROC & $0.80^{* * *}$ & $0.82^{* * *}$ & $0.78^{* * *}$ & $0.63^{* * *}$ \\
\hline
\end{tabular}

a Estimates are given as odds ratios.

$* * * \mathrm{p}<.001$

** $\mathrm{p}<.01$.

* $\mathrm{p}<.05$. 
The next step in the analysis involves comparing the performance of the fitted models with benchmark models that contain only the socio-demographics and the attitudinal constructs. As a final step a model including all variables is estimated.

To estimate the potential mediating effects predicted by H7, the bootstrap estimation method by Preacher and Hayes [62] was employed to measure the size of the indirect effects. If there are significant indirect effects of the benchmark variables via the previous generation variables, then mediation is confirmed. For each benchmark variable mediating effects were tested in a separate model, with the remaining benchmark variables as covariates. Each model contained 1000 bootstrap samples, as criterion for significance the $95 \%$ bias corrected and accelerated (BCA) confidence interval was used.

One issue to deal with in the estimation is the effect of age. Older consumers have been longer on the market and have therefore a larger likelihood to be an early adopter. To account for this we include a dummy variable that represents whether a consumer is over $35^{5}$ years old. The interaction of this dummy with the other independent variables represents possible differences between the older and younger age groups. However, these interaction terms had only very minor influences: a small effect in the model predicting early adoption of DVD-players and no effect for any of the other product generations. They are not further reported. The limited influence of age is confirmed by the results of the benchmark model in the next section.

\section{Results}

Table 2 displays the results of the stepwise logistic regression models, first for the previous generation model, next the benchmark model and thirdly a combined model that includes all relevant predictors. All estimators are presented as odds ratios to allow for easier interpretation and comparison of effect sizes: a ratio $<1$ means a negative effect, while a ratio $>1$ means a positive effect on early adoption likelihood.

\subsection{Previous generation model}

Model results confirm that consumers who have a previous product item available for use are more likely to have been early adopters, which supports H1. The exception is DVD-player adoption, for which no significant effect of availability of VCR is observed. In the DVD-recorder adoption model the effect of DVD-player availability indicates that consumers who currently have a DVD-player are less likely to have been early adopters of DVD-recorders (odds ratio $<1$ ), while people without a DVD-player are more likely to have been early adopter of DVD-recorders (odds ratio $>1$ ). Further, people who currently have a VCR are more likely to have been early adopters of DVD-recorders. This suggests that many held on to their VCR, not buying a DVD-player, and instead waited until the DVD-recorder became available. This represents an example of leapfrogging, which is the skipping of a product generation in anticipation of a better future alternative [28]. In the PVR model a similar effect is observed: the effect of DVD-player availability is much larger than the effect of DVD-recorder availability. This similarly suggests that early adopters of PVR at least partly consisted of consumers who skipped the recorder altogether and instead immediately adopted a PVR. This is not the case for Bluray/HDDVD adoption, for which the most recent generation item (DVD-recorder) is more predictive than availability of an earlier generation item.

Whether the consumer has bought the most recent previous product him or herself has a significant positive relationship with early adoption for all products in our study, which supports H2. In all models, having purchased the most recent previous generation has a positive relationship with early adoption of the current generation. Further, the effect of the most recent generation is stronger than earlier generations except for the PVR adoption model. Both these findings are in line with our theoretical reasoning. In the PVR model, it can be seen that both the 'purchased DVD-player' and 'purchased DVD-recorder' variables help explain PVR adoption, which probably represents the effects for different subgroups who had either previously adopted players or recorders but not per se both.

For adoption time the model shows significant effects on early adoption for all models. In the DVD-player and recorder models the effects are all positive indicating a greater time since adoption is associated with earlier adoption of the new product. This supports H3; however for the PVR model, while a similar positive effect is observed for the DVD player, a negative effect (oddsratio $<1$ ) is observed for DVD recorder purchase timing. This indicates that respondents who more recently adopted a recorder are less likely to have adopted PVR, which is against H3. H3 is therefore only partially supported.

Comparing the effects of the different generations per model it appears that availability, purchase experience and adoption times are not always more predictive for the most recent generations. Only in the recorder adoption model the effect of availability is strongest for the most recent generation, so we reject H4a. For purchase experience three of the four models are directly in accordance with the hypothesis (the most recent generation showing the largest effect), so we accept H4b. Regarding time of adoption the hypothesis is only supported for the DVD-player and DVD-recorder models, so there is only partial support for H4c.

In sum all three types of previous generation variable significantly contribute to the prediction of early adoption of successive generations. When considering the effectiveness of the three types of previous generation variables, it appears that when predicting early adoption for the two older products (DVD-player and recorder) the most effective predictor is whether the consumer has personally purchased the previous generation, although adoption timing also contributes to the prediction. Mere

\footnotetext{
${ }^{5}$ This cut-off value assumes that consumers over 35 were on the market at the time of market introduction of a certain product. We also applied other cut-off dates, these produce similar results.
} 
availability in the household of a previous generation item is the most effective variable when predicting adoption of the latest generations (Bluray/HDV and PVR). Availability of a VCR however also plays a significant role when predicting early adoption of DVD-recorders. Timing of adoption of previous generations is particularly important for predicting DVD-player adoption; it plays a less role in predicting adoption of the most recent products.

\subsection{Benchmark and combined models}

We next estimated models using only the benchmark variables. Results are in Table 2. ROC performances are barely acceptable while the PVR model is showing a poor performance in predicting early adoption. These performances are substantially worse than those observed for the previous generation models. The benchmark models nevertheless show some significant effects of sociodemographics. Gender is only significant when predicting early adoption of DVD-players, with males being almost twice as likely to have adopted early (H5a partly accepted). Age is only significant as a predictor of early adoption of DVD-recorders, with older respondents being more likely to have been early adopters (H5b partly accepted). Income is significant in both the DVD-recorder and the PVR model, with higher incomes being more likely to be early adopters (H5c accepted). Education is only significant in the DVD-recorder model, with higher early adoption levels for lower education levels, which is opposite to what was expected (H5d rejected).

Concerning consumer attitudes, CNS (Consumer Novelty Seeking) and CIJM (Consumer Independent Judgment Making) are not significant in any of the models (H6a and H6b rejected). Higher levels of DI (Dispositional Innovativeness) are associated with higher levels of early adoption of DVD-players and recorders and of PVR, which confirms H6c, and CSNI (Consumer Susceptibility to Normative Influence) contributes significantly to the prediction of early adoption of the newest products (Bluray/HDDVD and PVR), confirming H6d.

Given the difference in model performance we conclude that $\mathrm{H7}$ is confirmed: the previous generation model by itself predicts better than the benchmark model. We now add the benchmark variables to the previous generation model. The addition of these variables leads to a significant improvement in all previous generation models except the Bluray/HDDVD model. The combined PVR model performs relatively poorly $(\mathrm{ROC}<0.7)$ while all other models perform acceptably well $(\mathrm{ROC}>0.7)$ or excellently (ROC $>0.8$ ). The significant increases in model performance indicate that the additional (benchmark) variables explain a substantial part of the variance remaining after controlling for the previous generation model variables in three of the four models. As in model 2, gender predicts early adoption of DVD-players but there is now also an effect of age, with older respondents more likely to have adopted DVD-players early. Income continues to predict DVD-recorder and PVR adoption but there are no other effects of demographics. The effects of the attitudinal variables are not very different between model 2 and model 3.

The bootstrap estimates (results not shown here) revealed in the models predicting DVD-player and DVD-recorder adoption, positively significant mediating effects of age and DI. In the same models negative mediating effect was found for CSNI. No mediating effects were found in other models. The effect of age comes from the fact that older consumers, had more opportunity to adopt VCR-products and recorders earlier. In total the contribution of the other demographics to predicting early adoption of a next product generation after adding adoption of previous products to the model is limited.

The mediating effects by DI and CSNI operate through previous generation variables, which is in line with our explanation for $\mathrm{H7}$. Both are mainly mediated by the adoption time of previous generations. The mediating effects in the models are relatively small however. Overall, the prediction of early adoption of new product generations from attitudinal variables is relatively independent from adoption behavior displayed for previous generations. Further these effects are not generalizable across product generations.

\section{Conclusions and discussion}

\subsection{Conclusions}

This paper investigated the relationship between a consumer's adoption behavior displayed for previous product generations and early adoption of newer generation products. In general the models based on previous generation data outperform the benchmark models, although a combined model gives the best results.

Model results indicate that, as hypothesized (H1, 2 and 3), availability in the household, individual purchase experience and time of adoption of previous generations of a product all help to successfully predict early adoption of a succeeding generation, although support for the time of adoption hypothesis (H3) was mixed. We also found only mixed support for the hypothesis (H4a, $\mathrm{b}, \mathrm{c}$ ) that these effects are strongest for the most recent generation, the strongest support being observed for purchase experience.

The relative importance of these three predictors varied across the models. Experience with purchasing the most recent generation appeared as the most effective predictor of early adoption for the two oldest products, which is understandable given this experience will be easier to remember and better marks previous adoption than the two other variables, availability and purchase timing. Availability showed also strong influences, with strong positive effects for the pre-previous generation and negative effects for the most recent generation for two of the four models (DVD-recorders and PVR). In both cases this suggests that consumers have skipped a generation and leapfrogged DVD-players when adopting DVD-recorders, and were leapfrogging DVD-recorders when adopting PVR. This is indicative of a dual market, as recently studied for the pharmaceutical market by Vakratsas and Kolsarici [63]. Time of adoption was less predictive for the newer products probably due to the relatively short time these products have been on the market, which allows for little variation between the having purchased and time of adoption variables. 
The models that only include socio-demographic and attitudinal variables perform worse than previous generation models (H7). The individual socio-demographic variables had nevertheless some significant effects, as stated in H5. Education had little effect and showed even an opposite effect than expected for DVD-recorders, with lower early adoption associated with higher education levels. The overall limited predictive ability of the socio-demographic variables is consistent with earlier findings for consumer electronics [e.g. 13,46]. Using socio-demographics to predict the adoption of specific products typically produces poor results. This is because many specific situational factors can influence the decision to adopt a product at a certain moment in time [4,31].

The attitudinal constructs had also only limited predictive ability although we found confirmation for our hypothesis (H6) with Dispositional Innovativeness contributing significantly to predicting early adoption for three of the four studied products, and Consumer Susceptibility to Normative Influence contributing significantly to predicting early adoption of the most recent product generations. A possible explanation for the worse performance of this construct for the earlier generations is that the models attempted to explain past behavior (early adoption of the DVD-player and DVD-recorder) from currently held attitudes, as the data was based on retrospective reports. Respondents' current attitudes may well have changed since the moment of product adoption. Consumer Novelty Seeking and Consumer Independent Judgment Making did not contribute to any of the models. This poor performance can possibly be explained by the fact that these attitude items are phrased in quite general terms [50,64], which reduces their predictive value for concrete behavior.

\subsection{Limitations}

Whereas our models were successful in predicting early adoption for successive generations, issues concerning product category selection, sampling and measurements limit the generalizability of our findings. First, we only studied video play products. The study focused on this product category because it is relatively easy to distinguish different product generations within this category. Video play products can be deemed quite typical for the larger group of consumer electronics however it remains an empirical question whether our results generalize to other product groups.

Second, although the sample was randomly drawn within quotas that are broadly representative of the national population, the sampling frame only included internet users. The excluded consumers, non-internet users, are presumably those who are typically late in adopting new products. Including them however would not likely change the results as early adoption is defined as a proportion of adopters; we tested different proportions but obtained similar results.

Another sampling issue concerns mortality effects. The sample was derived from the population of current consumers, which is different from the consumer population at the time previous product generation appeared on the market. Although these sampling limitations are important to be aware of, they do not affect the main findings and conclusions from the current study because the study concerns the prediction of early adoption of successive generations from data as available for the current market place.

A third limitation is that the measurement of the time of adoption was based on recall. Recall data is prone to certain biases [65] and will have affected the extent to which our data represented respondents' real adoption histories. The recall problems were partly remedied by providing the respondents with broad response categories that made answering the question easier for the respondent. Future research should consider using a longitudinal survey design to obtain more reliable measurements but note that such data is difficult to obtain, given the time span for some of the products covered here extend over many years (up to almost 40 years for VCRs).

\subsection{Implications}

This paper contributes to the theories and methods of adoption behavior by arguing how adoption behaviors displayed for previous product generations relate to early adoption of successive generations and by presenting an approach to modeling this relationship using relatively easy to obtain data. Further, it described adoption patterns for a category of home entertainment products for which the continuous appearance of new successive generations is a prominent feature. In this way the current research particularly complements the earlier studies by Kim et al. [28] and Sääksjärvi and Lampinen [29].

The practical implication of this paper exists in the ability to obtain better predictions of early adoption behavior from measurable customer variables. This is particularly important for new product launches. The main advantage of using data on previous adoption behavior is that it often easy to obtain. For example, in a diagnostic sales interaction with prospective customers such information is more natural to obtain than socio-demographic and attitudinal information, as the latter require questions of a more obtrusive nature. Customer databases are also more likely to contain purchase history information than data regarding predictors conventionally used in adoption models.

The findings from the present study further imply that marketers should consider using data about customers' purchase histories to segment and target consumers who are most likely to be early adopters of new product generations. Such segmentation could be more efficient than segmenting on socio-demographic characteristics.

\section{Acknowledgments}

This study was conducted with funding from the Australian Research Council, Discovery grant DP0450910. 


\section{Appendix A. Correlation matrix of all adoption related variables}

\begin{tabular}{|c|c|c|c|c|c|c|c|c|c|c|c|c|c|}
\hline & $\begin{array}{l}\text { Early } \\
\text { adoption } \\
\text { DVD- } \\
\text { player }\end{array}$ & $\begin{array}{l}\text { Early } \\
\text { adoption } \\
\text { DVD- } \\
\text { recorder }\end{array}$ & \multicolumn{2}{|c|}{$\begin{array}{l}\text { Early adoption } \\
\text { Blu-ray player or } \\
\text { HD-DVD player }\end{array}$} & $\begin{array}{l}\text { Early } \\
\text { adoption } \\
\text { PVR }\end{array}$ & $\begin{array}{l}\text { Available } \\
\text { VCR }\end{array}$ & $\begin{array}{l}\text { Available } \\
\text { DVD- } \\
\text { player }\end{array}$ & $\begin{array}{l}\text { Available } \\
\text { DVD- } \\
\text { recorder }\end{array}$ & $\begin{array}{l}\text { Purchased } \\
\text { VCR }\end{array}$ & \multicolumn{2}{|c|}{$\begin{array}{l}\text { Purchased } \\
\text { DVD- } \\
\text { player }\end{array}$} & \multirow[t]{2}{*}{$\begin{array}{l}\text { Purchased } \\
\text { DVD- } \\
\text { recorder }\end{array}$} & $\begin{array}{l}\text { Adoption } \\
\text { time VCR }\end{array}$ \\
\hline $\begin{array}{l}\text { Early adoption DVD- } \\
\text { recorder }\end{array}$ & 0.21 & & & & & & & & & & & & \\
\hline $\begin{array}{l}\text { Early adoption Blu- } \\
\text { ray player or HD- } \\
\text { DVD player }\end{array}$ & -0.07 & 0.04 & & & & & & & & & & & \\
\hline Early adoption PVR & 0.12 & -0.01 & 0.22 & & & & & & & & & & \\
\hline Available VCR & 0.07 & 0.10 & 0.05 & & 0.00 & & & & & & & & \\
\hline Available DVD-player & 0.08 & -0.08 & 0.01 & & 0.11 & 0.27 & & & & & & & \\
\hline $\begin{array}{l}\text { Available DVD- } \\
\text { recorder }\end{array}$ & 0.07 & 0.26 & 0.18 & & 0.09 & 0.12 & 0.17 & & & & & & \\
\hline Purchased VCR & 0.17 & 0.14 & 0.09 & & 0.07 & 0.34 & 0.21 & 0.11 & & & & & \\
\hline $\begin{array}{l}\text { Purchased DVD- } \\
\text { player }\end{array}$ & 0.23 & 0.12 & 0.05 & & 0.13 & 0.12 & 0.40 & 0.17 & 0.51 & & & & \\
\hline $\begin{array}{l}\text { Purchased DVD- } \\
\text { recorder }\end{array}$ & 0.09 & 0.54 & 0.23 & & 0.11 & 0.07 & -0.01 & 0.50 & 0.17 & & & & \\
\hline Adoption time VCR & 0.27 & 0.18 & -0.17 & & 0.00 & -0.01 & 0.03 & 0.01 & 0.00 & & & 0.00 & \\
\hline $\begin{array}{l}\text { Adoption time DVD- } \\
\text { player }\end{array}$ & 0.64 & 0.22 & -0.14 & & 0.06 & 0.09 & 0.03 & 0.06 & 0.09 & & & 0.00 & 0.42 \\
\hline $\begin{array}{l}\text { Adoption time DVD- } \\
\text { recorder }\end{array}$ & 0.22 & 0.65 & -0.17 & & -0.07 & 0.10 & -0.05 & 0.00 & 0.06 & & & 0.00 & 0.26 \\
\hline Sex & -0.10 & -0.01 & 0.00 & & -0.07 & 0.04 & -0.01 & -0.15 & 0.03 & -0 & & 0.01 & -0.07 \\
\hline Age & 0.03 & 0.08 & -0.01 & & -0.04 & 0.12 & -0.07 & -0.06 & 0.30 & & & 0.09 & 0.24 \\
\hline $\begin{array}{l}\text { Education level } \\
\text { completed }\end{array}$ & 0.00 & -0.05 & 0.05 & & 0.03 & 0.01 & 0.01 & -0.01 & -0.06 & -0 & & -0.10 & -0.07 \\
\hline Income & 0.04 & 0.06 & 0.04 & & 0.13 & 0.00 & 0.07 & 0.09 & -0.07 & -0 & & 0.04 & -0.04 \\
\hline $\mathrm{CSN}$ & 0.06 & 0.06 & 0.04 & & 0.06 & 0.03 & 0.09 & 0.13 & -0.01 & & & 0.07 & -0.02 \\
\hline CIJM & -0.03 & -0.04 & 0.09 & & -0.03 & -0.08 & -0.06 & 0.06 & -0.06 & -0 & & 0.00 & -0.03 \\
\hline DI & 0.15 & 0.11 & -0.06 & & 0.10 & 0.01 & 0.09 & 0.07 & 0.11 & & & 0.09 & 0.15 \\
\hline \multirow[t]{2}{*}{ CSNI } & -0.09 & -0.11 & 0.13 & & 0.04 & -0.07 & -0.08 & -0.01 & -0.18 & -0 & & -0.04 & -0.24 \\
\hline & & \multicolumn{2}{|c|}{$\begin{array}{l}\text { Adoption time } \\
\text { DVD-player }\end{array}$} & \multicolumn{2}{|c|}{$\begin{array}{l}\text { Adoption time } \\
\text { DVD-recorder }\end{array}$} & Sex & Age & \multicolumn{2}{|c|}{$\begin{array}{l}\text { Education level } \\
\text { completed }\end{array}$} & Income & CSN & CIJM & DI \\
\hline & 0.35 & & & & & & & & & & & \\
\hline \multicolumn{2}{|c|}{$\begin{array}{l}\text { Adoption time DVD-recorder } \\
\text { Sex }\end{array}$} & -0.06 & & -0.04 & & & & & & & & & \\
\hline \multicolumn{2}{|c|}{ Age } & 0.02 & & 0.06 & & 0.03 & & & & & & & \\
\hline \multicolumn{2}{|l|}{$\begin{array}{l}\text { Education level } \\
\text { completed }\end{array}$} & -0.03 & & 0.01 & & -0.01 & -0.19 & & & & & & \\
\hline \multicolumn{2}{|l|}{ Income } & 0.06 & & 0.02 & & -0.18 & -0.36 & 0.37 & & & & & \\
\hline \multicolumn{2}{|l|}{ CSN } & 0.03 & & 0.03 & & -0.20 & -0.13 & 0.10 & \multicolumn{3}{|c|}{0.14} & & \\
\hline \multicolumn{2}{|l|}{ CIJM } & -0.11 & & -0.08 & & -0.22 & -0.01 & -0.04 & \multicolumn{2}{|c|}{-0.08} & 0.17 & & \\
\hline \multicolumn{2}{|l|}{ DI } & 0.15 & & 0.10 & & 0.00 & 0.00 & 0.03 & \multicolumn{2}{|c|}{0.10} & 0.19 & -0.13 & \\
\hline \multicolumn{2}{|l|}{ CSNI } & -0.19 & & -0.12 & & -0.10 & -0.21 & 0.07 & 0. & 04 & 0.18 & 0.24 & -0.32 \\
\hline
\end{tabular}

\section{References}

[1] G. Digital Entertainment, Press Release: DEG Year-End 2008 Home Entertainment Sales Figures, Digital Entertainment Group, Los Angeles, 2009.

[2] E.M. Rogers, Diffusion of Innovations, 5th ed. Free Press, New York, 2003.

[3] F.J. Van Rijnsoever, C. Castaldi, Extending consumer categorization based on innovativeness: intentions and technology clusters in consumer electronics, J. Am. Soc. Inf. Sci. Technol. 62 (2011) 1604-1613.

[4] D.F. Midgley, G.R. Dowling, Innovativeness: the concept and its measurement, J. Consum. Res. 4 (1978) 229-242.

[5] E.C. Hirschman, Innovativeness, novelty seeking and consumer creativity, J. Consum. Res. 7 (1980) $283-295$.

[6] G. Roehrich, Consumer innovativeness - concepts and measurements, J. Bus. Res. 57 (2004) 671-677.

[7] E. Von Hippel, Democratizing Innovation, MIT Press, Cambridge, MA, 2005.

[8] C. Lüthje, Characteristics of innovating users in a consumer goods field - an empirical study of sport-related product consumers, Technovation 24 (2004) 683-695.

[9] E.P. Katz, P.F. Lazarsfeld, Personal Influence, The Free Press, New York, 1964.

[10] E.M. Rogers, D.G. Cartano, Methods of measuring opinion leadership, Public Opin. Q. 26 (1962) 435-441.

[11] G. Cestre, R.Y. Darmon, Assessing consumer preferences in the context of new product diffusion, Int. J. Res. Mark. 15 (1998) $123-135$

[12] H. Gatignon, T.S. Robertson, A propositional inventory for new diffusion research, J. Consum. Res. 11 (1985) $849-867$.

[13] M.D. Dickerson, J.W. Gentry, Characteristics of adopters and non-adopters of home computers, J. Consum. Res. 10 (1983) $225-235$.

[14] A. Vishwanath, G.M. Goldhaber, An examination of the factors contributing to adoption decisions among late-diffused technology products, New Media Soc. 5 (2003) 547-572.

[15] R. Larose, D. Atkin, Audiotext and the reinvention of the telephone as a mass medium, Journal. Q. 69 (1992) $413-421$. 
[16] F.J. Van Rijnsoever, C. Castaldi, Perceived technology clusters and ownership of related technologies: the case of consumer electronics, J. Am. Soc. Inf. Sci. Technol. 60 (2009) 381-392.

[17] A. Vishwanath, H. Chen, Technology clusters: using multidimensional scaling to evaluate and structure technology clusters, J. Am. Soc. Inf. Sci. Technol. 57 (2006) 1451-1460.

[18] R. Bussele, J. Reagan, B. Pinkleton, K. Jackson, Factors affecting Internet Use in a saturated-access population, Telemat. Inf. 16 (1999) $45-99$.

[19] L. Leung, R. Wei, Who are the mobile phone have-nots? New Media Soc. 1 (1999) 209-226.

[20] P.P. Saviotti, J.S. Metcalfe, A theoretical approach to the construction of technological output indicators, Res. Policy 13 (1984) 141-151.

[21] J.H. Pae, D.R. Lehmann, Multigeneration innovation diffusion: the impact of intergeneration time, J. Acad. Mark. Sci. 31 (2003) $36-45$.

[22] P.J. Danaher, B.G.S. Hardie, W.R. Putsis, Marketing-mix variables and the diffusion of successive generations of a technological innovation, J. Mark. Res. 38 (2001) 501-514.

[23] J.A. Norton, F.M. Bass, A diffusion-theory model of adoption and substitution for successive generations of high-technology products, Manag. Sci. 33 (1987) 1069-1086.

[24] C. Michalakelis, D. Varoutas, T. Sphicopoulos, Innovation diffusion with generation substitution effects, Technol. Forecasting Soc. Chang. 77 (2010) 541-557.

[25] V.B. Kreng, H.T. Wang, A technology replacement model with variable market potential - an empirical study of CRT and LCD TV, Technol. Forecast. Soc. Chang. 76 (2009) 942-951.

[26] C. Castaldi, R. Fontana, A. Nuvolari, 'Chariots of fire': the evolution of tank technology, 1915-1945, J. Evol. Econ. (2009) 545-566.

[27] K. Frenken, L. Leydesdorff, Scaling trajectories in civil aircraft (1913-1997), Res. Policy 29 (2000) $331-348$.

[28] N. Kim, R.K. Srivastava, J.K. Han, Consumer decision-making in a multi-generational choice set context, J. Bus. Res. 53 (2001) $123-136$.

[29] M. Sääksjärvi, M. Lampinen, Consumer perceived risk in successive product generations, Eur. J. Innov. Manag. 8 (2005) $145-156$.

[30] S.J. Liebowitz, S.E. Margolis, Path dependence, lock-in, and history, J. Law Econ. Organ. 11 (1995) $205-226$.

[31] F.J. Van Rijnsoever, A.R.T. Donders, The effect of innovativeness on different levels of technology adoption, J. Am. Soc. Inf. Sci. Technol. 60 (2009) 984-996.

[32] M. Sujan, Consumer knowledge - effects on evaluation strategies mediating consumer judgments, J. Consum. Res. 12 (1985) 31-46.

[33] J. Gregan-Paxton, D.R. John, Consumer learning by analogy: a model of internal knowledge transfer, J. Consum. Res. 24 (1997) $266-284$.

[34] E.J. Johnson, J.E. Russo, Product familiarity and learning new information, J. Consum. Res. 11 (1984) 542-550.

[35] R.D. Blackwell, P.W. Miniard, J.F. Engel, Consumer Behavior, Harcourt College Publishers, Fort Worth, 2001.

[36] J.W. Alba, J.W. Hutchinson, Dimensions of consumer expertise, J. Consum. Res. 13 (1987) 411-454.

[37] M.K. Chang, W.M. Cheung, V.S. Lai, Literature derived reference models for the adoption of online shopping, Inf. Manag. 42 (2005) 543-559.

[38] M. Schreier, R. Prugl, Extending lead-user theory: antecedents and consequences of consumers' lead userness, J. Prod. Innov. Manage. 25 (2008) $331-346$.

[39] B.L. Bayus, S. Gupta, An empirical analysis of consumer durable replacement intentions, Int. J. Res. Mark. 9 (1992) $257-267$.

[40] R.L. Celsi, J.C. Olson, The role of involvement in attention and comprehension processes, J. Consum. Res. 15 (1988) $210-224$.

[41] J.B. Schmidt, R.A. Spreng, A proposed model of external consumer information search, J. Acad. Mark. Sci. 24 (1996) $246-256$.

[42] T.C. Boyd, C.H. Mason, The link between attractiveness of “extrabrand" attributes and the adoption of innovations, J. Acad. Mark. Sci. 27 (1999) 306-319.

[43] L. Leung, Lifestyles and the use of new media technology in urban China, Telecommun. Policy 22 (1998) $781-790$.

[44] R. Aversi, G. Dosi, G. Fagiolo, M. Meacci, C. Olivetti, Demand dynamics with socially evolving preferences, Ind. Corp. Change 8 (1999) $353-408$.

[45] P.L. Ziamou, R.W. Veryzer, The influence of temporal distance on consumer preferences for technology-based innovations, J. Prod. Innov. Manag. 22 (2005) 336-346.

[46] A. Vishwanath, Impact of personality on technology adoption: an empirical model, J. Am. Soc. Inf. Sci. Technol. 56 (2005) $803-811$.

[47] R.E. Goldsmith, C.F. Hofacker, Measuring consumer innovativeness, J. Acad. Mark. Sci. 19 (1991) $209-221$.

[48] S. Im, B.L. Bayus, C.H. Mason, An empirical study of innate consumer innovativeness, personal characteristics, and new-product adoption behavior, J. Acad. Mark. Sci. 31 (2003) 61-73.

[49] R. Garcia, R. Calantone, A critical look at technological innovation typology and innovativeness terminology: a literature review, J. Prod. Innov. Manag. 19 (2002) 110-132.

[50] R.E. Goldsmith, J.B. Freiden, J.K. Eastman, The generality/specificity issue in consumer innovativeness research, Technovation 15 (1995) $601-612$.

[51] A.C. Acock, M.L. DeFleur, A configurational approach to contingent consistency in the attitude-behavior relationship, Am. Sociol. Rev. 37 (1972) 714-726.

[52] F. Bartiaux, Does environmental information overcome practice compartmentalisation and change consumers' behaviours? J. Cleaner Prod. 16 (2008) $1170-1180$

[53] S. Owens, 'Engaging the public': information and deliberation in environmental policy, Environ. Plann. A 32 (2000) $1141-1148$.

[54] H. Lee, J. Ryu, D. Kim, Profiling mobile TV adopters in college student populations of Korea, Technol. Forecast. Soc. Change 77 (2010) 514-523.

[55] K.C. Manning, W.O. Bearden, T.J. Madden, Consumer innovativeness and the adoption process, J. Consum. Psychol. 4 (1995) 329-345.

[56] J.B.E.M. Steenkamp, K. Gielens, Consumer and market drivers of the trial probability of new consumer packaged goods, J. Consum. Res. 30 (2003) 368-384.

[57] J.B.E.M. Steenkamp, F. ter Hofstede, M. Wedel, A cross-national investigation into the individual and national cultural antecedents of consumer innovativeness, J. Mark. 63 (1999) 55-69.

[58] W.O. Bearden, R.G. Netemeyer, J.E. Teel, Measurement of consumer susceptibility to interpersonal influence, J. Consum. Res. 15 (1989) $473-481$.

[59] K. Jöreskog, D. Sörbom, LISREL, Scientific Software International, Inc, 2006.

[60] A.R.T. Donders, G.J.M.G. van der Heijden, T. Stijnen, K.G.M. Moons, Review: a gentle introduction to imputation of missing values, J. Clin. Epidemiol. 59 (2006) 1087-1091.

[61] T. Fawcett, An introduction to ROC analysis, Pattern Recognit. Lett. 27 (2006) 861-874.

[62] K. Preacher, A. Hayes, Asymptotic and resampling strategies for assessing and comparing indirect effects in multiple mediator models, Behav. Res. Methods 40 (2008) 879-891.

[63] D. Vakratsas, C. Kolsarici, A dual-market diffusion model for a new prescription pharmaceutical, Int. J. Res. Mark. 25 (2008) $282-293$.

[64] I. Ajzen, Attitudes, personality and behavior, 2nd ed. Open University Press, Berkshire, England, 2005.

[65] S.F. Gardial, D.S. Clemons, R.B. Woodruff, D.W. Schumann, M.J. Burns, Comparing consumers' recall of prepurchase and postpurchase product evaluation experiences, J. Consum. Res. 20 (1994) 548-560.

Frank J. van Rijnsoever is an Assistant Professor of Innovation Studies in the Copernicus Institute of Sustainable Development, Utrecht University, Utrecht, The Netherlands. He received his PhD from Utrecht University in 2010. His research interests are, among others, in innovativeness, technology adoption and in understanding preferences on the demand side of innovation (consumer choice and early adoption). He published in Research Policy, Journal of the American Society for Information Science and Technology (JASIST) and in Transportation Research Part-D. (Email: f.vanrijnsoever@geo.uu.nl).

Harmen Oppewal is a Professor of Marketing in the Department of Marketing at Monash University, Melbourne, Australia. He received his PhD from the Technical University of Eindhoven in The Netherlands. His research interests are in consumer behavior, consumer decision making and choice modeling in retail and service contexts. He published on these topics in journals such as the Journal of Marketing Research, the Journal of Retailing and the International Journal of Research in Marketing. (Email: Harmen.Oppewal@buseco.monash.edu.au). 